\title{
Using body cards in a design process for going from bodily experiences to design
}

\author{
Jakob Tholander \\ MobileLife@Stockholm University \\ Forum 100, 16440 Kista, Sweden \\ jakobth@dsv.su.se
}

\begin{abstract}
To build creative links between ethnographic findings of bodily practices and design, we developed so called body cards to document experiential qualities to be used in idea generation and early prototyping. These focus on the stages of a design process that involves investigating a use domain and making such knowledge relevant and usable for design. This involves challenges of effectively describing - with theoretical and empirical grounding - how bodily action and experience actually occur, in relation to people, artefacts, and activities. We discuss challenges in bridging between ethnographic findings and design of technologies for bodily experiences. Designing for the body in interaction is then not only about better ways of sensing bodily actions, but just as much about integrating these in the space of social interaction.
\end{abstract}

Bodily interaction, tangible interaction, design, embodiment.

\section{INTRODUCTION}

We present a design process in which a set of so called body cards was designed as a means of explicitly bringing in bodily experiential qualities as central elements. We focused on taking sensory and perceptive qualities such as movement, touch (Larssen, Robertson, and Edwards, 2007), gesture, (Hummels, Overbeeke, and Klooster, 2007) and haptics (Schiphorst, 2009) as the basic building blocks when designing for people"s experiences with and around technology, something that we find lacking in most current design approaches. By concentrating on bodily aspects of experience (Coffin, 2008; McCarthy \& Wright, 2004) we aim to contribute to a strand of work aiming to design for bodily action in close integration with various forms of indivuidual and social interaction. The design process resulted in a tangible device that allows groups of visitors to an art hall to share their experiences via physical traces that are created through touching and moving their device in various ways which has been presented in further detail elsewhere (Laaksolahti et al 2011). In this paper we target the stages of the design process that involves going from empirical investigations of a domain and making such knowledge relevant and usable for design. In the design process we focused on how bodily action can be taken as essential to everyday experiences and made relevant in design.
The body cards evolved during the design process as means to support designers firstly, to focus on users' engaged bodily action in designing interactive artefacts for social experiences, and secondly, to tailor the interaction in accordance to the specific circumstances of a particular unique real-life setting. This work illustrates one way of studying, analyzing, and designing for a particular setting in a theoretically grounded fashion. We focus on how bodily aspects of user experiences and social action can be made relevant, practically useful, and seen as opportunities and challenges in designing bodily engaging artefacts. The body cards were used in several different contexts of designing for whole body in interaction such as sports, education, and museum technology (see Figure 1 for card used to design sports technology). Here, we discuss a case from an art hall in Stockholm in which the body cards were central in designing for visitors to physically express themselves and to physically experience each other's impressions of their visits. This work takes a strictly experiential perceptive on the body in interaction that differs from other current conceptualizations of interaction on the body in interaction such as Reality Based Interaction (Jacob, et.al. 2008). Instead, our focus is in line with research work that specifically has investigated physically engaging activities with the purpose of teasing out design relevant experiential qualities such as (Höök, 2010; Tholander \& Johansson, 2010). 


\section{The devil is in the details}

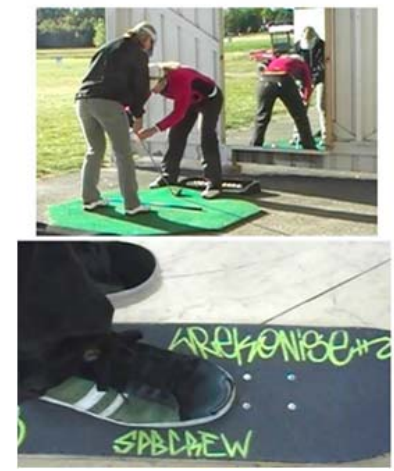

Small changes to details in standing, holding, pressing, etc the artefact has big consequences for how the movement is performed.

Golfers adjust there grip on the club, millimeter by millimeter.

Skateboarders talk about the importance of where to place his feet in regards to the screws on top of the board.

Figure 1: An example of a body card from sports

Firstly, we present the development of body cards and go into detail on how two of these were designed based on a theoretically grounded videobased interaction analysis. Secondly, we present how the cards were used in our design work, and how one of the design concepts that came out of the process, was further developed to a working prototype, and how the themes from the cards can be traced in this. We end by discussing challenges in finding essential experiential bodily qualities in empirical material, and how to make those useful and relevant in a design.

\section{BACKGROUND}

With the turn to embodied interaction, the design of collaborative technologies has increasingly stretched into our physical world. Many studies of physical interactive artefacts have shown how these successfully support social, collaborative, and embodied action in a range of different settings (e.g. Fernaues \& Tholander 2006; Hornecker \& Buur, 2006). In social and leisure-oriented contexts, we currently see a lot of exciting work that addresses how novel sensor and actuator technologies offer new materials that can potentially be used to design for bodily engaging experiences. This trend in interaction design puts the physicality of our bodies and its consequences for human action and perception at centre stage. This also brings along questions of how aspects such as the physical shape, form, texture, and size of interactive artefacts and settings influence and shape the kind of experiences people have. We argue however, that the focus of the body in much research are still primarily through explorations of new technical and functional properties of the physical artefacts, and less on the bodily kinds of action and experiences that these allow for. In design-oriented research on the other hand, we see an increasing number of attempts that start out from the human experiential perspective. Examples include those that map out experience-based interaction qualities such as suppleness (Isbister \& Höök, 2009) and pliability (Löwgren, 2007), as well as design frameworks for understanding the physiological dimensions of the body in interaction (Foghtmann, Fritsch, Kortbek, 2008) bodily aspects of human action and perception, and ways of making these relevant and usable in design (Hummels, Overbeke, and Kloster, 2007). We draw on themes from studies and theories of the role of bodily practices in meaning making and human thinking from philosophers such as Merleau-Ponty (2001), Sheets-Johnstone (2009), and tries to make them practically relevant in design. Theoretically, we start out from phenomenological perspectives on action and perception were Merleau-Ponty (2001) is a leading figure. He attempted to explain human perception in a nonrepresentationalist fashion with a focus on our corporeal existence and how the specific characteristics of our bodies shape our perception, sense-making, and action. In explaining human perception Merleau-Ponty did not make a separation between body and cognitive processes where one comes before the other. Rather he aimed towards showing how these are an integrated couple in a dynamically perceiving experiential body. Maxime Sheets- Johnstone's phenomenology of movement is an even more radical attempt to put body and movement at centre stage of human cognition. She extends the ideas of Merleau-Ponty by arguing not only for the corporeal grounding of perception, but placing specific emphasis on how movement of the body should be taken as the essential characteristic from which thinking and perception are built. Rather than viewing body movement as being controlled by mental processes, she proposes movement as the basis for cognitive processes, through the notion of thinking in movement. According to this, sensing the world and acting in it, do not belong to two separate domains, but are part of the same experiential world. Thereby, she shows how the idea of separating thinking from its expression, and the claim that a thought in the head exists prior to its expression, denies the idea of thinking and acting as a dynamic process created by a mindful body. Of particular relevance for the setting explored in this paper, there are several studies have also shown how subtle bodily interaction are key aspects of people's experiences at museum and art halls (e.g. vom Lehn, Heath and Hindmarsh, 2001). We also drew upon, Joy \& Sherry"s (2003) study on the individual aspects of museum visitors, and their use of Merleau-Ponty"s concepts of virtual body and imaginatory perception. These notions bring attention to a number of issues regarding the role of the body in the visitors' interaction, including how other senses than the one actually stimulated by a particular object can be invoked by it, e.g., how a picture of a flower can invoke not only visual experience, but 
actually let us have the experience of the smell of flowers.

We argue that these perspectives challenge how to investigate and theoretically approach experiential aspects of design of interactive artefact. This suggests a shift towards the interpretation of experience as a phenomenon grounded in bodily experiential qualities, and away from cognitively oriented perspectives. Examples of recent work addressing these challenges are (Schiphorst, 2009; Larssen et al, 2007), that explore the implications of pragmatist and phenomenological theories to develop design senstitivties for bodily engaging technologies.

\section{THE BODY CARDS}

From a design methodological point of view, the body cards were inspired by methods such as design games (Brandt \& Messeter, 2004), inspiration cards workshops (Halskov \& Dalsgård, 2006), video cards (Buur \& Söndergaard, 2000), and, The card brainstorming game (Hornecker, 2010), all with the aim to facilitate collaborative and inspirational design sessions. We also draw upon methods such as transfer scenarios (Ljungblad \& Holmqvist, 2007) and associative design (Esbjörnsson, Juhlin \& Östergren, 2004). These provide methods for transferring experiential qualities from people"s deep engagement in one practice to a different setting, by creating links that can be used in innovative design work, e.g. by using personas and word substitution.

Based on empirical studies of a targeted domain of use, the cards display particularly relevant phenomena, coupled with relevant theoretical and empirical understandings of the role of the body in interaction. The cards are developed to carry experiential qualities from a use domain by providing detailed understanding about movement, touch, gesture, and spatiality (as exemplified by the card in Figure 1), and also opening up for the creativity, interpretation, and empathy (Wright \& McCarthy, 2008) necessary in design work. They aim to support the creative linking between ethnographic findings of bodily practices, and idea generation and prototyping. In the design process we combined competences including ethnography, design and $\mathrm{HCl}$ supporting design teams in making "the imaginative and conceptual move" in creatively taking ethnographic insights to practical design work (Dourish, 2007). Importantly, there is not one general set of cards to be used in all kinds of design situations that focus on bodily engaging technologies. Rather, each design process requires the development of new and unique cards as a critical part of the actual design process. The body cards were developed in three main steps.
1. Conducting empirical investigations of a specifically chosen practice focusing on bodily ways of experiencing and acting. We use phenomenological perspectives on human experience as a lens to empathically view and understand human action and the bodily experiential qualities it involves.

2. Selecting findings with particular design relevance, typical as well as atypical events, and transform these into phenomenal descriptions represented through photographs and textual descriptions on cards.

3. Using the cards in design work for development of design concepts, lo-fi, and quick-and dirty prototyping.

The first step involved conducting an empirical investigation of a specific setting that one aims to design for. The investigations focus on bodily ways of communicating and interacting with and around artefacts and other people, in the environment. The analysis study bodily actions such as gesture, posture, gaze, use of artefacts, and other action directed towards artefacts and people. In this process, we drew on ethnomethodological and video-analytic research and how it has shown how bodily action, such as gesture and posture, play a key role in social interaction, see e.g. (vom Lehn, Heath \& Hindmarsh, 2001). However, since our studies have a clear design orientation we allow ourselves to diverge from some of the methodological rigour of much ethnomethodological work, and combine these with subjective interpretations of the participants" actions (Wright \& McCarthy, 2008). For instance, in our studies of bodily experience and movement in sports (see Figure 1), focus was on understanding participants' felt experiences of movement with the specialized artefacts used in the sport, while in the art hall setting, our focus was more on the communicative processes and expressions related to art exhibits. Our basic take is that the body is a significant aspect of all human experiences. Any experience therefore has an element of embodiment to it. However, for the purposes of design, bodily ways of acting and interacting plays a more prominent role in some situations than in others. Therefore, our work is largely about understanding experiences using a phenomenological perspective on body and experience as a critical lens. The second step involves transforming of the ethnographic findings into descriptions that capture phenomena with interesting, often subtle and discrete, bodily experiential qualities. The phenomena that we pick are not necessarily the most prominent in the findings, but should represent especially interesting situations in which bodily action worked as a key 
element, and work as inspirations for design. The findings are compiled into cards consisting of summarizing labels, snapshot photos illustrating a phenomenon from our video material, and longer formulations describing how the phenomenon unfolded in particular situations (Figure1).

\section{The urge to touch and feel}

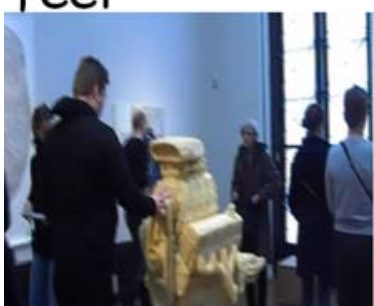

Touching is not allowed. Jeff is so anxious to touch the rubber engine that he makes an elaborated forming of his his hand to get as close as possible to a real touch.

Visitors often wanted to and even did touch the objects to feel texture, shape, material, relief effects of objects, especially sculpures invited tactile explorations

\section{Wandering around in circles}

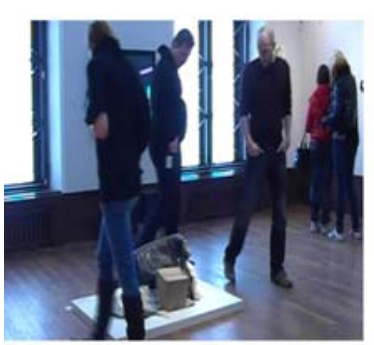

Jeff, Amande and Andy experienced the stray dog in silence. But were very much together in a coordinated walk around the art piece. Letting their bodies do the talking.

Visitors engage in bodily ways of collaboratively exploring objects in a coordinated fashion, varying distance and perspective to the art pieces

\section{Dancing eyes, fingers, and bodies to share experiences}

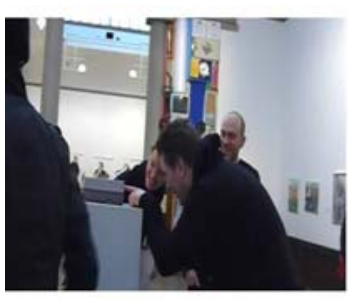

Jeff, Amanda, and Andy silenty explore the video game in the peep-hole by letting their eyes, fingers and bodies make the subtleties of the art piece come alive for them.

The visitors engaged in considerable collaborative action bodily as well as verbaly. Walking, positioning, gesturing played a key role in the engagement of sharing experiences

\section{Living the artist's hardship}

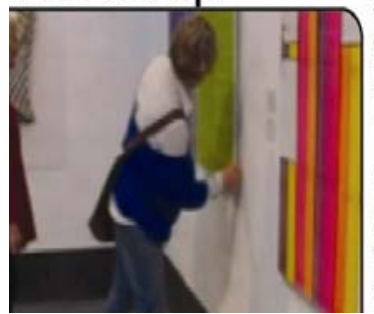

Kerrie investigates materials and structures with her hands. She wants to learn about if she could make the piece herself, or if this is something she would like in her home

Understanding how pieces are made, the materials and the techniques used are important to the experience of the art
Even though photos remove some of the interactive and dynamics from how the phenomenon originally played out, our experiences show that designers are highly skilled in adding such dimensions themselves. Each card should give an in-situ characterization of the key elements of the participants" actions of the situation it denotes, as well as a more general description that picks up on theoretical aspects of the phenomena. Thereby, we aim to provide accounts of the participants' lived, social, embodied experiences in a fashion that speak to the designers" empathic competences and engagement.

We chose to represent the phenomena as cards for a number of reasons. Firstly, cards have worked successfully as a representational form in a number of other design methods. This form also makes them easy to adapt to the specific circumstances of each setting. Secondly, the light-weight form makes them easy to move between settings and situations, and they can be used lying around as reminders of different aspects to focus upon. Thirdly, making the cards informationally lightweight and representationally straightforward, does not require complicated skills or training to use them. Fourthly, the format allows them to be used in different ways throughout the process.

The third step involves taking the cards into practical design work in design activities of different kind (e. g. random words, body storming, lived experience, lo-fi prototyping). Before using the cards in design we make a presentation of the empirical material to the design team to give them an overall sense of it. One example of a design exercise in which we used the body cards is random words. In the random words method, words from different categories, such as technology words and interaction words, are used in brainstorm for design ideas. The body cards can be used as one category of words. Another exercise in which we used the body cards was is body storming (Oulasvirta, Kurvinen \& Kankainen, 2003) where the cards served as a as an empirical grounding for the designers engagement in the specific bodily experiential qualities that people have had in the same real-life setting as they are currently acting out their ideas in. Thereby, allowing them to try to feel what it would be to have the kind of experience that they are sketching out in their designs. In such exercises, body cards play a central as well as peripheral roles in design work. Both as specific qualities to focus upon on in design, and as a reminder for designers to remain oriented towards and grounded in the characteristics of the ethnographic findings. In the following, we describe how the body cards was used in a designing for social experiences at an art hall.

Figure 2: Four body cards in the design process 


\section{BODY CARDS FOR AN ART HALL EXPERIENCE}

Based on the initial observations we zoomed in on particular aspects of how visitor groups interacted as they moved around in the exhibition hall. We then went back and made video recordings that aimed to capture what we had initially noted. In total, the visits of five groups were closely followed and about five hours of video was collected. The material was analyzed using interaction analysis as specified by our method. Attention was paid to how participants used their bodies as resources for interaction, and on bodily ways of interacting and expressing themselves throughout their visits. In particular, we analyzed the details of participants" interaction with and around the art, with each other, and with other aspects of the environment. Our analysis revealed a number of aspects with respect to social and collaborative interaction in the museum, many of them similar to findings of vom Lehn and Heath, et al, showing the importance of: a) how the conduct of others, both friends and strangers, shape how art is experienced, b) how visitors shape the vision and experience of others to create shared experience, c) how visitors make features of exhibits visible to each other through delicately designed physical and verbal action. This also included how visitors explored 3-dimensional models from different angles and how the size of objects provided particular bodily engagement and experiences. Moreover, visitors used their bodies to almost touch sculptures and paintings in order to create imaginative experiences of a sensation that they could not physically have, since touching art was not allowed. The Varsalongen exhibition at Liljevalchs art hall is a yearly event that has been going on since 1921. The exhibition invites professional as well as amateur artists to anonymously submit art pieces. Usually, about 34000 pieces are submitted. Among the submitted works, a jury selects about 250 pieces. The Varsalongen attracts a wide array of visitors ranging from people with a strong interest in art to people who have a yearly tradition to visit the exhibition, but rarely visit any other art exhibitions. The Varsalongen has a tradition of stirring up emotion and engagement both among visitors and in media.

\section{Ethnographic observation and analysis}

Our initial observations of visitors in the art exhibition hall showed that the art hall worked as a neutral arena for the visitors to be with one another in a relaxed fashion. They displayed different degrees of engagement with the art and with the social aspects of the visit, they shifted from engaging in the whole group to splitting into subgroups or as individuals. Sometimes the art was made an explicit topic while sometimes it was in the background of their attention, hence different degrees of engagement in the art were common and accepted within the groups.

\section{From ethnography to body cards}

Table 1 shows four of the body cards that were developed. Next, we will go in- depth into two of these to show how they were derived from the empirical findings. For each card we provide an excerpt chosen to illustrate properties that were prominent in this particular phenomenon. The purpose of these excerpts is not to give complete accounts of the visitors" experiences and interaction, but to provide a sense of the characteristics out of which the cards were derived.

\section{Card 1. The urge to touch and feel art pieces}

The urge-to-touch card picks up on notions from Merleau-Ponty on imaginatory perception and virtual body in interaction with a physical object, as well as how bodily actions are used for communicative purposes around an art piece. In Excerpt 1 we show how this phenomenon plays out in practical action in the Liljevalchs setting and how that was developed into the urge to touch-card.

\section{Excerpt 1.}

1.Johan: (approaches the piece) aahhh V8

2.Amanda: sometimes I kind of when I read the name of the art piece I think that one should get kind of more of what the idea behind it is

3.Anders: $\mathrm{mmm}$

4.Amanda: but sometimes it's kind of cryptical stuff 5.Johan: $\mathrm{mmm}($.) what's the name of this one then 6.Amanda: don't know

7.Johan: please don't touch (.) it's called I get so disappointed

8.Amanda: heh heh heh

9.Johan: I so much want oh feel and then they have one of those rude

(Johan moves hand right by part on piece)

10.Amanda: no it says [nothing

11.Johan: [don't you think (.) I really want to

(pretends to squeeze)

12.Amanda: do it do it [do it (nods)

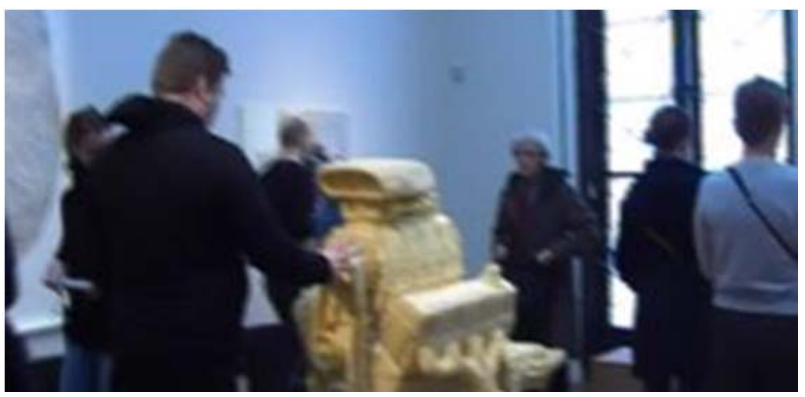

Figure 3: Pretends to squeeze sculpture with right hand 


\section{Johan: [heh I don't dare}

14.Amanda: obsessive thoughts

15.Johan: don't

16.Amanda: but what is it (.) it's some kind of machine or what

Here, Johan, Arvid and Amanda, three visitors at the art hall, approach a sculpture (titled As if), shaped and sewn out of foam rubber. As Johan approaches the piece, he exclaims 'ahhh' V8, identifying it as a V8 engine, using a tone of voice signaling appreciation and enjoyment.

Johan's initial exclamation about the V8 engine is not recognized by Amanda, who instead starts talking about how the art pieces in general are labelled. While Amanda is searching for a label, she catches up on Johan's increasing eagerness to touch the foam rubber sculpture (turns 10-12) and intensively monitor his gestures towards it.

It is clear that Johan emotionally connects to the piece through the way he expresses aaahh V8 in the first turn. In the continued interaction between him and Amanda, as they search for the label of the piece they discover another sign saying "Please, don't touch", which Johan refers to in line 7 when saying please 'don't touch (.) it's called (1.0 s)' I get so disappointed. This is the start of a playful interaction around the possibility of breaking the rule of not touching the art pieces. Amanda responds with a laugh, followed by a series of probing gestures (turn 9) aligned with verbal expressions of disappointment ending with the expressive physical action of Johan pretending to squeeze the piece (see Figure 3 ) with his right hand (turn 11).

The urge to touch card aims picks up on the tactile and material dimensions of Johan's and Amanda's experiences. Even though Johan never actually touches the piece, the elaborate action of forming his hand to physically imagine what he would like to do works as a way to 'haptically seeing' the piece. It is a way for himself to engage in the experience, and also a way of playfully expressing this to Amanda. Such a bodily expression provides opportunity for Amanda to use playful authority to persuade Johan to actually squeeze the piece. Central to the playfulness here is how Johan imaginatively experiences touching and its dual purpose. It is part of the social interaction going on, and essential to Johan's multi-sensory experience of the piece, and of visiting the art hall in general.

Card 2. Dancing eyes, fingers and bodies

This dancing eyes, fingers, and bodies card picks up on findings on how people collaboratively shape a shared experience through fine-tuned bodily actions. Excerpt 2 illustrates how this played out when Johan, Arvid and Amanda explored an art piece, titled Reveal 8-bit, a plastic box with a "peep hole" containing small figures playing a video game. The three friends engage in detailed work of coordinating body posture, gaze, and pointing, combined with verbal accounts to construct a shared experience of an art piece specifically crafted for individual viewing.

\section{Excerpt 2.}

1. Arvid: Somewhere there is a Nintendo

2. Johan: oh

3. Arvid: hehehe (.) peep hole (leans forwards and looks in the peep hole, leans back)

4. Johan:(leans forwards and looks) ah shit there are small figures in there

5. Arvid: Yeah ahaha

7. Arvid: (rises up) hehe

8. Johan: eh but is it a game in there too [some rally game

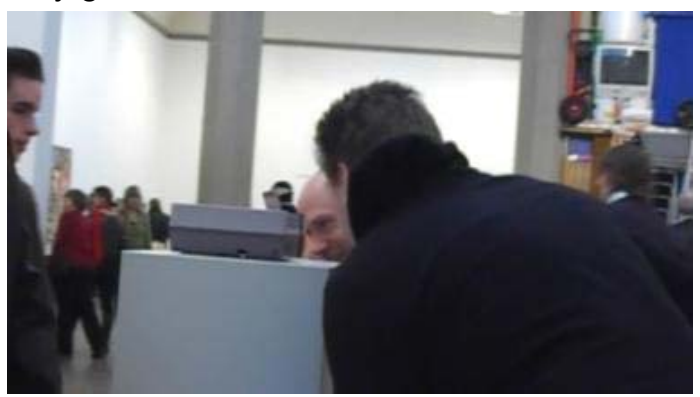

Figure 4: Collaboratively looking into peephole

9. Arvid: (bends forward, see Figure 4)[something (rises up)

10. Johan: can you see it from there too (leans to view from Arvids' angle, see Figure 5 below)

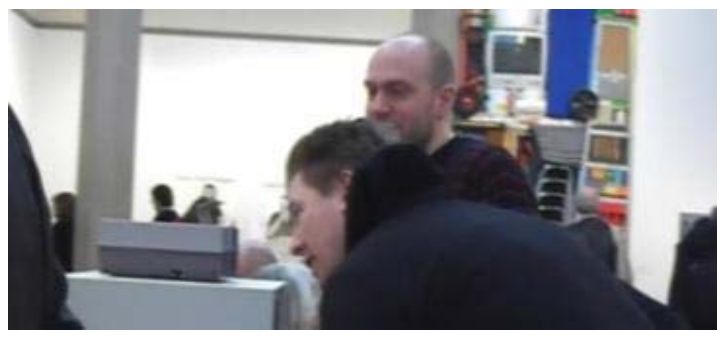

Figure 5: Shifts position to see from friends angle

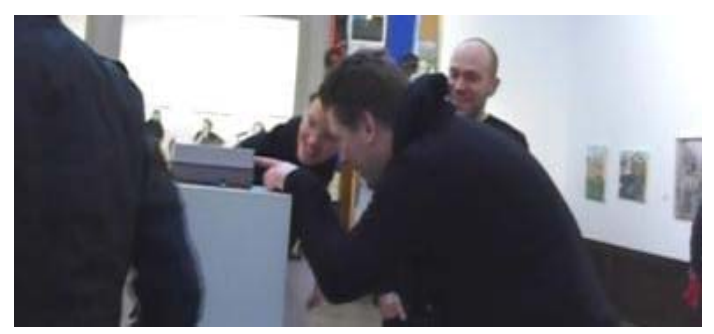

Figure 6: Points to confirm visual impression

11. Arvid: no (.) only (.) down there 
13. Johan: hey check this out (points the peep hole on the "whole" box ) [this we should have in our Wii room, huh

\section{Arvid: [ahhaha lets buy it}

15. Johan: there are small figures in (points straight in to the little peep hole, see Figure 6) this one and they have one (points to the left inside the box 15) screen there where you they sit and play (.) some rally game

\section{Amanda: ahhaha}

17. Johan: isn't that cool (4s) show it to Fred and he'll buy it on the spot

Arvid is the one who first approaches the piece followed by Johan. Arvid starts out by looking into the peep hole laughing and commenting peep hole (turn 3), with Johan standing behind him. When Arvid has finished looking, he leans back, providing a physical space that invites Johan to position himself next to him. This gives Johan an initial view into the peep hole and he says shit there are small figures in there and as he moves closer to see better, Arvid rises up to give Johan full access to the peep hole. Johan then makes a proposal for what it is that they are seeing: a game some rally game. This works as an invitation to Arvid to look again and they re-position themselves next to each other so that both get a partial, but temporally synchronized, view into the peep hole. As they both only have partial views into the peep hole they now attempt to establish that they both have seen the full piece as Johan asks Arvid: can you see it from there too, which he responds he can"t. Arvid then guides Johan so he can confirm that they share a visual experience of the piece. At this point, Amanda approaches them, and Johan shows her by explaining and pointing in a way that describes the different ways she should look into the peep hole. This works as an invitation to Amanda to share their experience of looking into the peep hole. The shared experience of the group is also further established through Johan's humorous association that they should buy the piece and bring it to their Wii-room at the office $(13,16)$.

The physical actions of looking together and collaboratively taking turns, getting and giving room to look into the very small peep hole, coordinated by quite detailed pointing actions and changes in posture build up a possibility for a shared experience of experiencing the art piece together. Elaborately tuned bodily actions contribute to a spatial organization that allows them to engage in a shared meaning making process. Amanda later joins them and smilingly starts to explore the art piece together with Johan without saying anything, rather displaying her curiosity through posture and facial expressions. This body card thus aims at capturing how verbal expressions rely on nonverbal possibilities for its unfolding, and vice versa.
Here, gaze, posture and gesture produce a collaborative experience that they take beyond this particular setting, by imagining how Fred should buy the piece and bring it to their office. Such a shared exploration of an artwork provides opportunity for the production of a deep and joyful experience that can spawn conversations and associations that contribute to maintaining and strengthen their relationship. This card picks up on these aspects of bodily communicative action and association.

\section{Taking the body cards to design}

Now let us move on to describe how the body cards were used in the practical design work, and some of the resulting concepts and early prototypes. The cards were used in design exercises in which the purpose was to develop design ideas and prototypes for bodily engaging technologies of being and experiencing together at the art hall. Much of the design work was conducted within the premises of the art hall allowing ideas and concepts to be tried out in-situ. The design team, of about 15 people, consisted of interaction designers, industrial designers, hardware, sensor and software engineers, as well as $\mathrm{HCl}$-specialists. In using the body cards in design we started out by giving the design team a presentation of the situations in the video material out of which they were derived and collaboratively analyzed short snippets of video. This gave the team a first understanding of the setting and the phenomena of specific interest that had been identified. We presented the body cards and how these related to our studies. The design process consisted of a number of design exercises, lo-fi prototyping, and attempts to imagine the experience of users. Bringing the body cards to a first iteration of designing for bodily ways of interaction in the art hall resulted in 35 design ideas with both strong and as well as weak links to the body cards. Three were further explored and we technically implemented a few critical aspects as working prototypes and tested these together with visitors at the art hall.

Two ideas generated that both draw on the card dancing eyes, fingers, and bodies were Copy cat and Compose with light. (Figure 7) In Copy cat an art object would mimic the user"s gestures and replay them for the next group approaching the object, giving an image of what the persons before expressed. In Compose with light users would write and draw on pictures with light using their hands or an object to point with, which could be recorded and replayed until a new group arrives. Examples of two ideas generated that both draw on the Urge to touch card were 3-d Touch Glove and Physical Flashlight. The 3-d Touch Glove would provide a glove that makes it possible to feel edges and structures on 
3-d objects from a distance, and the degree of sensation would increase from collaboration in the group. With the Physical Flashlight users would explore an object with a pointer and get force feedback, and the light would change colour depending on the nature of the surface.

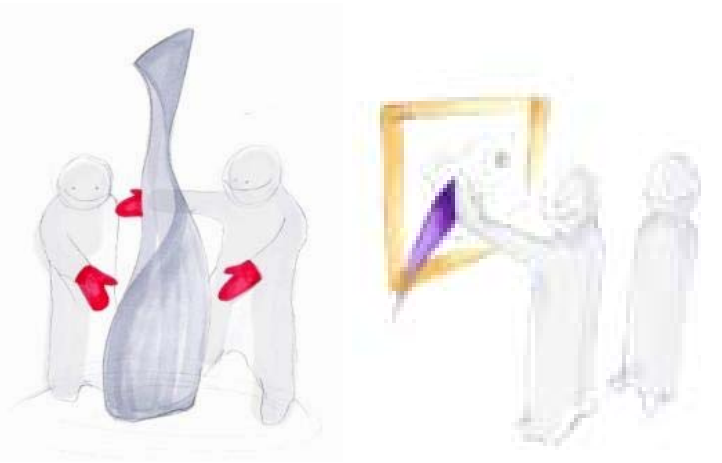

Figure 7. The 3-d glove, and Compose with light

Figure 8 shows participants in the design team acting out the 3-d touch glove at one of the art pieces in the art hall. The experience from this was that it only replicated the qualities expressed in the Urge to touch-card, without much novelty in terms of interaction. In this exercise, rather than working as design inspiration, the card gave the designers" a critical lens in evaluating their idea. The Compose with light was also quickly built into a lo-fi prototype. show visitors interacting around an art piece and how shades of their gestures were left on a surface in front of the piece.

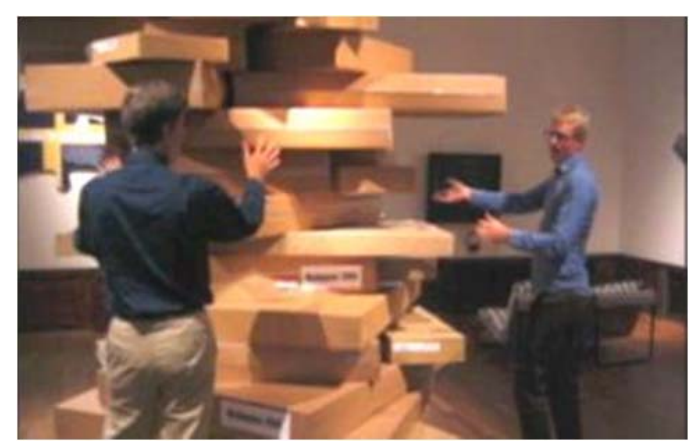

Figure 8. Body storming for the Touch glove

\section{THE LEGA PROTOTYPE}

A prototype called the Lega was one of the design concepts that was built into a first working prototype and tried out with visitors at the art hall. The key inspiration for this idea was the dancing eyes, fingers, and bodies and urge-to-touch cards that builds on observations of how visitors used the physical space to split up, re- gather, and invite each other to share experiences, and did substantial interactional work to share aspects of seeing, feeling, and imagining. The concept, called Lega, after a Swedish word for a place where an animal has rested, allows visitors to leave bodily traces at particular places around the exhibition. Visitors may experience an art piece and want to share this with their friends. Other members of the group can, while separately viewing the art, discover lega traces from their friends. The legas mark specific places that friends can visit to participate in a shared experience. The mere fact that a lega is positioned at specific spot may suggest to the rest of the group to creatively engage in its meaning, and create a shared the experience at the spot. The physical properties of the Lega would let the visitors create and experience physical expressions that connect to the particular place they are acting in.

A quick prototype was implemented using wireless sensors, sensor nodes and actuators capsulated in tricot covered styrofoam balls, communicating via radio, equipped with $3 \mathrm{D}$ accelerometers, LEDs, and a vibrators. Movement captured by the accelerometer were used to create lega expressions, and the vibrators were used to indicate that a particular place is of interest to others. When a friend is approaching a lega trace, the Lega vibrates. Visitors who want to express something to the others, creates a lega, by performing an open-ended bodily movement. The other members of the group can discover these through the physical feedback (light and vibration) they received at that spot, and creatively interpret the meaning of these from their bodily sensation and the context of the trace.

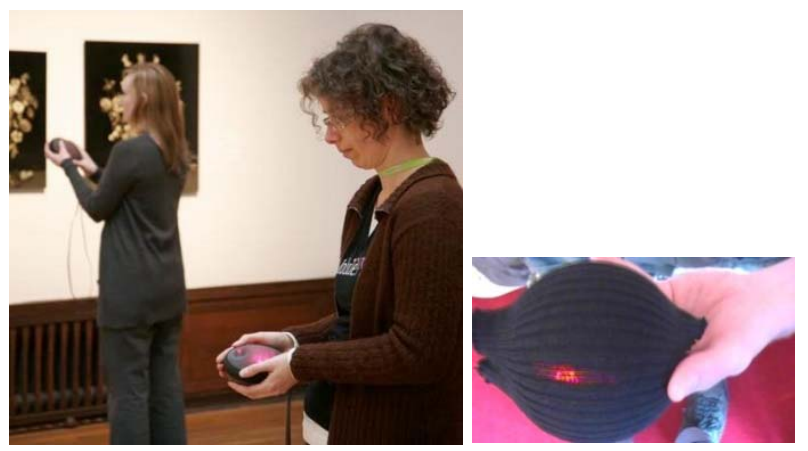

Figure 9. Lega user testing and first prototype

In a small user test of the prototype, a group of visitors were introduced to the prototype and encouraged to use it. The idea was positively received by the users who emphasised how this would allow them to prolong their engagement around an art piece and build conversations together with their friends. They expressed that there was a wide range of experiences that they would like to share, such as appreciation and depreciation of an art piece. Common memories induced by a specific object may inspire them to try to gather the group, reminding them and reliving 
the memory together. The physical input and output were said to reinforce the possibilities of associating to their friends' experiences.

\section{The Lega in relation to the body cards}

To assess the benefits of the body cards on the design process, we would like to reflect on the specific qualities from the body cards that the design of the Lega drew upon, and the form it took in this initial version. The Lega concept was developed from the specific observation of how visitors create shared experiences of art pieces. From the body cards we knew that visitors did substantial interactional work to make experiences shared around a number of different art pieces. One aspect of such a sharing process is that designers cannot know, and should not try to infer beforehand, around what objects that visitors engages in such a sharing process, and neither what bodily means they would be using. By taking inspiration from this body card, the design team designed an object that provides an opportunity for visitors to use their bodies to leave a subtle and ambiguous trace that a friend can re-experience in physical form. This can work as a starting point for a friend to reflect upon the meaning of the trace, using shared memories and associations that they have with the one who left the trace. The sharing can happen on the spot when the trace is picked up, and also as a conversational starter for friends to pick up on once they meet again. However, the meaning making and sharing that occurs around the Lega in visitors" real-life interaction, is left to their human competencies of empathising and engaging in their friend's experience.

\section{DISCUSSION}

We have presented elements of a design process that focused on how to incorporate bodily aspects of experience into the design of interactive artefacts. We have presented how we integrated ethnographic investigations of a use setting with theoretical and empirical insights in bodily interaction, and how were transformed into body cards. The cards captured essential qualities of bodily ways of being and interacting in the setting. The body cards are descriptive and non-technical in their form with the intention to portray what it is like to have a uniquely human experience in that setting. This work aims to speak to designers' competencies of emphatically imagining someone else's life world and to transfer relevant bodily experiential qualities to the design and crafting of interaction. We have focused upon externally observable aspects of bodily experiences such as facial expressions, laughing, body orientation, postures, gesture and movement, that participants produce in situ. However, there are also a range of subjective dimensions of such experiences that is not captured. Experiential aspects of a more subjective character such as the actual feeling of touching an object, or how smiles and body orientation contributes to bringing back personal memories and associations are other elements central to the experience. To design for such experiences we need to further explore subjective aspects of bodily experiences in design oriented ways. This involves challenges in describing how bodily action and experience actually occur, in relation to people, artefacts, and activities that they refer to. We need to find ways to extend other approaches such as video-analysis and Labananalysis, in order to also reach the subjective dimensions of bodily experiences. We also need to develop ways of formulating these in a fashion that speaks to designers' empathic competences to allow them to enter into the subjective and imaginative world of having these experience.

Coming back to the perspective on the body provided by theorists such Sheets- Johnstone and Merlau-Ponty, we argue that they pose a specific set of challenges and opportunities for designers technologies of bodily engaging interaction. In our design process we attempted to integrate these perspectives and use them as a lens in taking the whole human body into account in interpreting and transforming ethnographic findings of bodily experiential qualities into design relevant understandings. A particular quality pointed to in these perspectives is the inevitable dynamic characteristic of human perception. The challenge of putting dynamics at the core is that designers that attempt to design technologies for bodily engagement must tailor these to the limitations of the sensing capabilities of the computational material. Consequently, by representing real-life events through photos and textual descriptions also involve such a reduction. However, by closely tying the body cards to ethnographic findings, and by emphasizing the dynamics of human perception and sense-making, we argue that we can support designers in using this as an opportunity in design.

We demonstrated how the body cards shaped the interactional qualities of a number of design ideas, as well as in the Lega that was explored more in depth. The explorations revealed that visitors created rich meanings also around rather simple forms of output. A challenge that can be drawn from this regards how designers of technologies for physical interaction must consider bodily actions that are not conducted in immediate interaction with the technology, such as seemingly simple acts of standing or walking around. These basic actions must also be included as critical to a design process that aims to support an interaction where our whole bodies are meaningfully integrated in use of the artefacts. A simple physical input may play a key role in the richness of the user's perception and experience of the interaction. This requires 
designers to be sensitive not only to material qualities of e.g. how sensor technologies can be used to actively shape the interaction, but also to how to integrate these in a larger spaces of bodily meaning making practices. Designing for whole body interaction is then not only about better ways of sensing bodily actions, but just as much about integrating these in the space of social interaction.

\section{REFERENCES}

Brandt, E. and Messeter, J. (2004). Facilitating collaboration through design games. in PDC 04, ACM.

Buur, J. and Soendergaard, A.. (2000). Video card game: an augmented environment for user centred design discussions. in DARE '00, ACM.

Coffin, J. (2008). Robotany and Lichtung: a contribution to phenomenological dialogue, in TEI"08., ACM Press. Bonn, Germany.

Dourish, P. (2007). Responsibilities and implications: further thoughts on ethnography and design, in DUX'07. ACM Press..

Esbjörnsson, M., Juhlin, O., and Östergren, M. (2004). Traffic Encounters and Hocman Associating Motorcycle Ethnography with Design. Journal of Personal and. Ubiquitous Computing. 8(2): p. 92-99.

Fernaeus, Y. and Tholander. J. (2006). Designing for programming as joint performances among groups of children. Interacting with Computers, 18(5) p. 1012-1031.

Fogtmann, M.H., Fritsch, J., and. Kortbek, K.J (2008) Kinesthetic interaction: revealing the bodily potential in interaction design. in OZCHI'08. ACM Press.

Halskov, K. and Dalsgård, P. (2006). Inspiration card workshops. in DIS '06 University Park, PA ACM Press.

Höök, K. (2010). Transferring qualities from horseback riding to design. in NordiCHI ' 10. ACM Press.

Hornecker, E, and Buur, J. (2006). Getting a grip on tangible interaction: a framework on physical space and social interaction. CHI '06, ACM.

Hornecker, E. (2010). Creative idea exploration within the structure of a guiding framework: the card brainstorming game. in TEI '10, ACM.

Hummels, C., Overbeeke, K.C., Klooster, S (2007). Move to get moved: a search for methods, tools and knowledge to design for expressive and rich movement-based interaction. Journal of Personal. and Ubiquit Comp., 11(8): p. 677-690.
Isbister, K. and Höök, K. (2009) On being supple: in search of rigor without rigidity in meeting new design and evaluation challenges for $\mathrm{HCl}$ practitioners. in $\mathrm{CHI}$ '09. New York, NY, ACM:

Jacob, R., Girouard, A.,. Hirshfield, L.M., Horn, M.S., Shaer, O., Solovey, E.T., and Zigelbaum. J. (2008). Reality-based interaction: a framework for post-WIMP interfaces. in CHI '08, ACM.

Joy, A. and Sherry. J. (2003). Speaking of Art as Embodied Imagination: A Multisensory Approach to Understanding Aesthetic Experience. Journal of Consumer Research. 30: p. 259-282.

Laaksolahti, J., Tholander, J., Lundén, M., Solsona Belenguer, J., Karlsson, A., \& Jaensson, T. (2011). The Lega: A Device for Leaving and Finding Tactile Traces. TEI 2011, ACM.

Larssen, A.T., Robertson, T. and Edwards, J. (2007). The feel dimension of technology interaction: exploring tangibles through movement and touch, in TEl'07. ACM Press. Baton Rouge, Louisiana. p. 271 - 278.

Ljungblad, S. and Holmquist, L.E. (2007). Transfer scenarios: grounding innovation with marginal practices, in CHI'07,: San Jose, CA, ACM Press.

Löwgren, J. (2007). Inspirational patterns for embodied interaction. Journal of Knowledge, Technology \& Policy, 20(3).

McCarthy, J. and P.C. Wright, (2004). Technology as Experience. MIT Press, Cambridge, MA.. Merleau-Ponty, M (2001). Kroppens fenomenologi. Göteborg. Daidalos.

Oulasvirta, A., Kurvinen, E., and Kankainen, T. (2003). Understanding contexts by being there:case studies in bodystorming. . J.of Pers and Ubiquitous Comp. 7(2): p. 125-134.

Schiphorst, T. (2009). soft(n): toward a somaesthetics of touch, in $\mathrm{CHI}$ "09. Boston, MA, ACM Press.

Sheets-Johnstone, M. (2009). The corporeal turn: An Interdisciplinary Reader. Exeter, UK: Imprint Academic.

Tholander, J. and Johansson, C. (2010). Design qualities for whole body interaction: learning from golf, skateboarding and BodyBugging. NordiCHI '10. ACM,

vom Lehn, D., Heath, C., and Hindmarsh, J. (2001). Exhibiting Interaction: Conduct and collaboration in museums and galleries. Symbolic Interaction. 24: p. 189--216.

Wright, P. and J. McCarthy. (2008). Empathy and experience in $\mathrm{HCl}$. in $\mathrm{CHI} 08$. 